\title{
KAKO TUDI S SLABŠIM DMR DO USPEŠNIH APLIKACIJ
}

\author{
Dalibor Radovan
}

UDK 528.9:681.3

Izvleček

Opisan je postopek korekcije in analize natančnosti uradnega DMR-100 za celo Slovenijo. Kot alterantiva je naveden projekt digitalne baze reliefa, ki temelji na digitalnih plastnicah. V smislu izboljšave DMR sta obdelana pomen in smiselnost uporabe interpolacijskih metod. Na koncu je predstavljenih pet aplikacij DMR-100 s področja kartografije, prostorskega planiranja, radiodifuzije in višje geodezije.

UDC 528.9:681.3

Abstract

SUCCESSFUL APPLICATION OF FUZZY DEM DATA

The methods of correction and error analysis for the official $100 \times 100 \mathrm{~m}$ DEM of Slovenia is described. As alternative, the project of digital terrain data base with digital contours is proposed. Spatial interpolation methods are briefly mentioned in the sense of their usability for DEM enhancement. At the end, five applications based on DEM are presented for the purposes of cartography, planning, radiodiffusion and geodesy.

\section{UVOD - KRATKA ZGODOVINA DIGITALNEGA MODELA RELIEFA V SLOVENIJI}

Digitalni model reliefa s stometrsko mrežo (DMR-100) je bil v Sloveniji zajet $v$ sedemdesetih letih iz temeljnih topografskih načrtov (TTN) $v$ merilih $1: 5000$ in $1: 10000$. V času, ko je nastajal, se je začela pojavljati tudi prva programska oprema s tega področja, ki je bila $v$ glavnem omejena na preprostejše aksonometrične prikaze terena in nekatere celične aplikacije v SYMAP tehniki. DMR-100 je bil predstavljen kot sestavni del prostorskega informacijskega sistema (PIS), (Banovec, Lesar 1975). V praksi pa je resnično zaživel šele ob koncu osemdesetih let, ko je razvoj mikroračunalnikov omogočil uporabo geoinformacijske infrastrukture $v$ digitalni obliki tudi uporabnikom izven raziskovalne sfere.

Mag. Dalibor Radovan, dipl. ing. geod., Inštitut za geodezijo in fotogrametrijo, Ljubljana 


\section{IZVEDBA KOREKCIJ IN NATANČNOST POPRAVLJENEGA DMR-100}

Žal se je izkazalo, da obstoječi DMR-100 vsebuje obilico napak, ki so iz različnih vzrokov nastale pri zajemu podatkov. $Z$ naraščajočim zanimanjem za uporabo DMR-100 je rasla tudi potreba po generalni reviziji in korekciji nadmorskih višin. Leta 1990 je Republiška geodetska uprava pri Inštitutu za geodezijo in fotogrametrijo (IGF) naročila projekt odpravljanja grobih pogreškov.

Višine so bile originalno ocenjene s pomočjo plastnic na načrtih, zajem pa je opravljal v ta namen samo delno priučen kader (študenti, risarke, geometri). Odstopanja so $v$ glavnem nastopila iz naslednjih res raznovrstnih vzrokov:

- napačno ocenjena smer padanja (naraščanja) terena - pogrešek od 1 do $100 \mathrm{~m}$,

- napačno odčitana glavna plastnica - pogrešek 50, 100 ali več metrov,

- napaka pri štetju plastnic - običajno $5 \mathrm{~m}$ pri TTN 5 ali $10 \mathrm{~m}$ pri TTN 10 ,

- napake zaradi slabe ocene višin pod pogojnimi znaki za skalovje, melišča, itd. - pogreški tudi čez $100 \mathrm{~m}$,

- namerna malomarnost, hitro odčitavanje na oko - pogreški do $50 \mathrm{~m}$ in celo več na velikih površinah,

- grobi pogrešek pri shranjevanju (vpisovanju) višin v datoteko - pogreški celo do $1000 \mathrm{~m}$,

- namerno zaokrožanje višin - pogrešek do polovice ekvidistance,

- napačne koordinate enega ali več blokov po 100 višin,

- rotacija ali zrcaljenje bloka 100 višin zaradi neupoštevanja formata zapisa (neznanje in malomarnost),

- napake kartografskega materiala zaradi nepravilnih oznak plastnic in kot terena,

- drugi znani in neznani vzroki.

Pogreške smo iskali na več načinov; celoten DMR-100 smo trikratno prečesali:

- z aksonometričnim izrisovanjem blokov 10 x 10 višin - odkrivanje vizualno grobih pogreškov,

- z aksonometričnim izrisovanjem več blokov skupaj - odkrivanje neskladij med bloki in na robovih,

- matematično $z$ nelinearno interpolacijo in primerjavo izračunanih višin $z$ danimi višinami DMR-100. Toleranco odstopanja smo prilagajali tipu terena.

Programska oprema je bila izdelana na IGF. V splošnem smo ugotovili, da je odstopanja pod 20 metri (odvisno tudi od razgibanosti terena) težko $z$ gotovostjo identificirati. $\mathrm{V}$ sklopu te naloge smo izvedli tudi primerjalno analizo odstopanj med bazo geodetskih točk, ki imajo terensko na $1 \mathrm{~cm}$ 
natančno izmerjene višine in popravljenim DMR-100. Upoštevali smo 17000 geodetskih točk, ki leže v nivoju terena. Z nelinearno interpolacijo smo iz DMR-100 ponovno izračunali višino vsake geodetske točke in jo primerjali $z$ višino iz dane baze. Izločili smo tudi točke, ki so bile iz različnih vzrokov po nadmorski višini grobo napačne $v$ primerjavi $z$ DMR-100. Pri valorizaciji rezultatov smo pri vsaki točki matematično upoštevali frekvenčno in amplitudno razgibanost lokalnega reliefa. Tako smo dobili naslednje vrednosti za višinsko natančnost popravljenega DMR-100 (Radovan, 1990b):

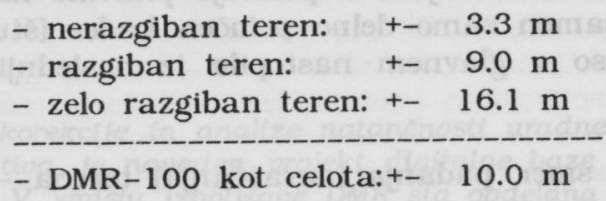

Kljub vsem naporom pa smo se tudi po izvršeni korekciji še vedno srečevali s pogreški baze DMR-100, predvsem zaradi napačnih celotnih blokov velikosti $1 \mathrm{~km}^{2}$. Te smo sproti ponovno zajeli oziroma popravili. Dejstvo je, da niti vizualne niti matematične metode ne odkrijejo popolnoma vsega, temveč pogrešek opazimo šele pri konkretni uporabi podatkov, zato je tudi zgornjo oceno natančnosti treba jemati nekoliko $\mathrm{z}$ rezervo.

\section{DIGITALNA BAZA RELIEFA KOT ALTERNATIVA OBSTOJEČEMU DMR-100}

Leta 1991 je IGF kandidiral na natečaju za izvedbo projekta digitalnega informacijskega sistema reliefa, ki ga je razpisalo Ministrstvo za varstvo okolja in urejanje prostora. Baza reliefa je bila pri tem le eden izmed predvidenih slojev geoinformacijske infrastrukture. Prav tako so bili vključeni tudi katastra zemljišč in zgradb, ter bazi infrastrukture in hidrografije. Zahteve za izvedbo projekta so bile $\mathrm{v}$ kratkem naslednje:

- orientiranost na objekte. kot nosilce informacij,

- korporiran grafično-atributni pristop, oziroma možnost transfera podatkov v GIS,

- ohranitev natančnosti originalnih podatkov v okviru natančnosti metode zajemanja,

- zajem $s$ skaniranjem in vektorizacijo oleat načrtov $v$ merilih 1:500 in $1: 5000$,

- izris založniških originalov na dimenzijsko stabilni foliji po geodetskih standardih natančnosti in po kartografskem ključu,

- izmenjava podatkov s soizvajalci,

- izdelava predlogov za bodoče GIS-funkcije, generalizacijo, modele zajemanja, kvalitete in zanesljivosti, upravljanje, hranjenje in vzdrževanje baze. 
Za testno območje okolice Šentjerneja pri Kostanjevici smo zajeli kompletne oleate reliefa kot tri vsebinske sloje (Radovan, 1992a):

- plastnice,

- lomne linije in

- točkovne elemente in kote terena.

Izdelana sta bila objektni in signaturni katalog za vse možne objekte, ki nastopajo $\mathrm{v}$ zgornjih treh slojih. Na vsak objekt je bilo navezanih tudi po nekaj atributov, ki opredeljujejo zajem, kvaliteto in zanesljivost podatkov. Delo je bilo opravljeno s PC verzijo ARC/INFA, AutoCADom, ter različno pomožno programsko opremo za skaniranje, digitalizacijo, avtomatsko vektorizacijo, grafično editiranje, transformacije, interpolacije, generalizacijo linij, ter konverzijo podatkovnih formatov. Del opreme je bil že predhodno razvit na IGF, ostalo pa so kupljeni licenčni programi.

Ker naj bi bila baza večnamenska oziroma prilagojena uporabnikom GIS orodij, je bila ena od predvidenih aplikacij tudi generiranje DMR poljubne gostote direktno iz digitalnih plastnic in kot terena. $\mathrm{V}$ ta namen smo izvedli analizo natančnosti zajetih plastnic $\mathrm{v}$ primerjavi $\mathrm{z}$ bazo merjenih geodetskih točk testnega območja na podoben način, kot je to opisano $v$ prejšnem poglavju 2. Srednji pogrešek primerjave originalnih in nelinearno interpoliranih nadmorskih višin geodetskih točk iz digitalnih plastnic in kot je odličen: $+-0.71 \mathrm{~m}$, kar nam kaže na to, da bi tako zastavljena baza reliefa resnično lahko predstavljala alternativo starejšemu DMR-100, vendar ob precej višji ceni zajema.

\section{VLOGA INTERPOLACIJSKIH METOD PRI MODELIRANJU RELIEFA}

Interpolacijske metode igrajo pri modeliranju reliefa zelo pomembno vlogo, včasih pa celo pomembnejšo, kot jim v resnici pripada. Vsekakor nam mora biti jasno, da od interpolacije ne moremo pričakovati več kot od podatkov samih, pa naj bo metoda še tako dodelana in natančna. To nam pove tudi izrek o vzorčenju (sampling theorem) iz Fourierove analize periodičnih funkcij (Brigham 1988, Kraus 1984). Če namreč relief obravnavamo kot periodično funkcijo neke valovne dolžine, potem lahko $z$ vzorčenjem te ploskve dobimo povratno popolno informacijo le, če je interval vzorčenja manjši od polovice te valovne dolžine. To pa pomeni, da iz preredkega, npr. stometrskega grida nima smisla interpolirati višin na 10 metrov, ker smo pri zajemu stometrskega grida avtomatsko izgubili vse morfološke oblike terena, ki so manjše od 50 metrov.

Interpolacija pride torej $\mathrm{v}$ poštev le pri prediciranju pojavov, ki so pomanjkljivo zajeti, ne pa tudi tistih, ki sploh niso zajeti zaradi preredkega, oziroma neustreznega vzorčenja. Kljub vsemu pa v primerih, ko ni zahtevana visoka natančnost, vendarle lahko uporabimo interpolacijo za glajenje, zgoščevanje ali manj natančno predikcijo npr. obstoječega DMR-100. 
Na IGF so bile $\mathrm{v}$ bližnji preteklosti opravljene obsežne raziskave tako točkovnih, kot tudi arealnih prostorskih interpolacijskih metod (Radovan, 1988a, 1988b, 1990a). Pri tem so bile programirane in preizkušene naslednje nelinearne variante - navedene po stopnji kompliciranosti, ki delno ponazarja tudi kvaliteto interpolacije:

- kriging - štirje različni modeli variogramov z ali brez "nugget" efekta, nelinearna optimizacija za "fitting" modela,

- metoda najmanjših kvadratov s kovariančnimi funkcijami,

- Gaussova kovariančna funkcija $z$ nelinearno optimizacijo,

- bikubični zlepki (spline) - trije različni robni pogoji,

- Hardyeva metoda $z$ multikvadratnimi enačbami - tri različne jedrne funkcije,

- trend funkcije - trije različni redi,

- metoda distančnih uteži - štiri različne utežne funkcije z regulacijo glajenja,

ter dodatno še arealna piknofilaktična metoda, ki pride $\mathbf{v}$ poštev predvsem za modeliranje in napovedovanje gostot in podobnih tematskih pojavov.

Na testnih območjih različnih razgibanosti je bil raziskan prag natančnosti, pod katerega se $z$ interpolacijo pri DMR-100 ne moremo več pomakniti, ne glede na sofisticiranost metode. Informativno naj navedem samo dve vrednosti teh pragov:

- približno $5 \mathrm{~m}$ za pretežno nerazgiban teren in

- približno 25 metrov za zelo razgiban hribovit svet.

Pri tem se rezultati različnih metod bistveno ne razlikujejo med seboj. Razlika se pokaže šele pri natančnejših in gostejše zajetih DMR! Podobno sklepanje najdemo tudi v članku (Makarovič, 1972), kjer avtor celo predlaga uporabo najnavadnejše linearne interpolacije za preredko vzorčene ploskve.

\section{IZBRANI PRIMERI APLIKACIJ DMR-100 S PROGRAMI IZDELANIMI NA IGF}

\section{ANALITIČNO KARTOGRAFSKO SENČENJE}

Analitično senčenje reliefa za potrebe klasične kartografije je v svetu uporabljano že precej časa, čeprav sprva na precej primitivni ravni (Yoeli 1965), kar pa je bilo pogojeno predvsem $z$ razvojem ustreznih rastrskih risalnikov. Klasično kartografsko senčenje je mukotrpen in za eno samo karto tudi po več tednov trajajoč proces. Na IGF je bil z razvojem ustrezne programske opreme ta proces skrajšan za 10 do 20 krat (Rozman, Radovan, 1985, Radovan, 1992b). 
Postopek temelji na računskem ugotavljanju refleksij celic DMR-100 potem, ko se izbere neka fiktivna osvetlitev. Ta je lahko lokalno prilagojena terenskim robovom, $\mathrm{ki}$ se jih mora predhodno digitalizirati in matematično navezati na DMR. Senčenje se ne podreja splošnemu Lambertovemu fizikalnemu zakonu, ki ga uporabljajo CAD programi, temveč vključuje psihološko-kognitivna dognanja percepcije senčenja na karti (Imhof, 1965). Bistvene razlike so $\mathrm{v}$ osvetlitvi s severne nebesne poloble, da se izognemo inverznemu efektu, in $v$ lokalnih modulacijah osvetlitve. Program, napisan v Turbo Pascalu, omogoča naslednje avtomatske posege $v$ vsebino slike:

- lokalno prilagajanje horizontalnega in vertikalnega kota osvetlitve terenskim oblikam,

- korekcije kontrasta in osvetlitve $\mathrm{v}$ odvisnosti od nadmorske višine,

- maskiranje ravninskih delov terena,

- invertiranje slike,

- uporabo 64-tonske skale psevdoslučajnostnih rastrov, ki omogočijo poltonski, izredno kvaliteten izris,

- zgoščevanje DMR z različnimi interpolacijskimi metodami,

- glajenje in ostritev robov (grebenov),

- izris na laserski in matrični tiskalnik ter ekran.

Izrise senčenja $s$ to metodo smo pred kratkim uporabili za poizkusni tisk karte občine Ljubljana-Šiška (IGF) in izseka Julijskih Alp (Geodetski zavod RS). Obe karti sta $v$ merilu 1:50.000.

\section{"OVERLAY" RASTRSKIH KART HIPSOMETRIJE, NAKLONOV, OSONČENJA, EKSPONIRANOSTI IN VRŽENIH SENC}

Eni od prvih, ki so začeli uporabljati podatke DMR-100, so bili v Sloveniji urbanisti in prostorski planerji. Pri svojem delu izdelujejo kompozitne analize, ki jih dobe s prekrivanjem vsebine različnih prostorskih baz. Podatki o oblikovitosti terena igrajo pri tem zelo pomembno vlogo.

Potreba po računalniških analitskih kartah, ki niso nič drugega kot "overlay" v GIS tehnologiji, ali pa oleate v klasični tematski kartografiji, se je v Sloveniji pojavila že precej let pred pojavom prvega ARC/INFA na našem tržišču. Ker smo DMR-100 že imeli, potrebne programske opreme pa pri nas še ni bilo, smo leta 1986 razvili programe, ki delujejo na nivoju rastra oziroma pixlov, in katere smo kasneje še večkrat dodatno nadgrajevali (Rozman, Radovan, 1991). Ti omogočajo:

- izris hipsometrične karte,

- izris karte naklonov,

- izris karte jakosti osončenja,

- izris karte vrženih (naravnih) senc terena,

- izris karte eksponiranosti,

- izris analitske karte s prekrivanjem dveh do petih zgornjih kart. 
Pri vsaki karti je možen tudi izhod v obliki matrike zaradi kasnejših numeričnih analiz ali trodimenzionalnega aksonometričnega prikaza tematike. Kot spremljajoča vsebina se lahko izrišejo tudi dodatno digitalizirani linijski in točkovni elementi.

Poseben pomen ima tu zadnja, analitska opcija. Ta omogoči na primer formiranje karte, ki prikazuje samo celice, ki so nižje od 500 m, imajo naklon do 10 stopinj, ter pri osončenju $z$ jugozahoda pod kotom 30 stopinj niso $v$ senci. Podobnih kombinacij je lahko nešteto, lahko pa nam pomagajo pri kvalifikaciji primernosti terena za različne dejavnosti, kot so na primer:

- kmetijstvo (vinogradništvo, poljedelstvo),

- urbanizem (lokacija in orientiranost posameznega objekta),

- načrtovanje tras daljnovodov,

- načrtovanje smučišč, itd.

Skratka, dosežena je funkcionalnost programske opreme na podobni ravni, kot jo ponujajo današnja komercialna orodja GIS.

\section{PROSTORSKA VIZUALIZACIJA RABE PROSTORA}

Del programskega paketa DMR (Rozman, Radovan, 1991) predstavlja tudi aksonometrični prikaz terena $z$ vrisanimi točkovnimi, linijskimi ali arealnimi elementi, ki jih moramo predhodno digitalizirati. Zaključene areale, kot je na primer raba prostora, je treba navezati na posamezne celice DMR tako, da jih dvignemo na odgovarjajočo nadmorsko višino, ter ugotovimo pripadnost celice izbrani vrsti rabe tal. V treh dimenzijah se vsaka celica prikaže $\mathbf{s}$ šrafiranjem $\mathbf{v}$ tisti barvi, ki ustreza konkretni rabi. Ker je v model možna hkratna vključitev linij (ceste, reke) in točk (objekti), nam je $s$ tem omogočena vizualizacija kompletnega terena $v$ poljubnem pogledu.

Uporabnost takšnih prikazov je predvsem v možnosti simulacij in vizualizacij idejnih projektov različnih zajezitev, izkopov, gradnje cest in sečnje gozdov. Seveda pa nista zanemarljivi tudi preglednost in grafična atraktivnost pri prezentacijah tako laikom kot strokovnjakom.

\section{VIDNOST IN SENCE SIGNALOV RADIOTELEVIZIJSKIH ODDAJNIKOV}

Za uporabnike s področja radiodifuzije in radarskih sistemov je vprašanje dometa, vidnosti in senc oddanih signalov vitalnega pomena za uspešno opravljanje dejavnosti. Še preden pričnejo $z$ gradnjo RTV oddajnika, morajo opraviti raziskave terena $v$ bližnji in tudi relativno oddaljenejši okolici okrog predvidene lokacije objekta. Še pred uvedbo računalniških rešitev je to pomenilo obsežna računanja smeri, v katerih žarkovje oddajanja zadane 
$\mathrm{v}$ terensko vzpetino in prekine signal, kar pomeni nastanek radijske (ali radarske) sence. Vsak oddajnik naj bi seveda imel čim manj takšnih mrtvih območij, zato se naprave postavljajo na čim bolj izpostavljene lokacije. Sprejem oziroma vidnost signala se je $v$ preteklosti računala iz plastnic na topografskih kartah.

$\mathrm{Na}$ IGF je bila za te potrebe razvita programska oprema, ki uporablja podatke DMR-100, in ima naslednje lastnosti in funkcije (Rozman, 1991):

- izračun in 3D aksonometrični izris arealov senc signala,

- izračun in 2D izris žarkovja vidnosti (sprejema) signala,

- upoštevanje atmosferske refrakcije in ukrivljenosti Zemlje,

- vris točkovnih objektov pri obeh načinih izrisa (naselja, drugi oddajniki),

- maksimalni radij dometa je $75 \mathrm{~km}$ okrog oddajnika.

Izris aksonometrije je podoben kot pri vizualizaciji rabe prostora iz prejšnjega poglavja 5.3. Tlorisni izris izgleda kot koncentrično, mestoma prekinjeno žarkovje $\mathrm{z}$ gostoto ene stopinje ali več.

\section{OPTIMIZACIJA RAČUNANJA TOPOGRAFSKIH ODKLONOV VERTIKALE}

Kot zanimivost naj na koncu omenim še uporabo DMR v višji geodeziji, kjer nas ponavadi zanimajo mase in privlačnost kamnin pod površino terena.

Že precej daljnega leta 1984 smo DMR uporabili pri raziskavah ploskve geoida v Sloveniji (Radovan, 1984a, 1984b, Vodopivec et al, 1985). Pri tem nas je zanimala gravitacija mase kamnin $v$ bližnji in tudi zelo daljni okolici astro-geodetskih točk visoke preciznosti. Veliki presežki in primanjkljaji mase (hribi in doline) namreč $v$ odvisnosti od oddaljenosti $z$ različno močjo vplivajo na smer težiščnice, ter s tem tudi na obliko geoida, ki predstavlja nulto ekvipotencialno ploskev. Ta fizikalni efekt ima za posledico korekcijo koordinat zaradi takoimenovanega topografskega odklona vertikale. Raziskava je dala kot rezultat optimalni vzorec gostote DMR (variabilna velikost celice) za različne tipe terena, ter enačbe za topografske odklone vertikale, ki so bile izpeljane za prizmatoide kamnin pod celicami DMR. Kot osnova je služil uradni DMR-100, ki ga je bilo potrebno lokalno še razredčiti ali zgostiti. Optimizacija je bila $v$ celoti izvedena računalniško na tedanjem univerzitetnem računalniku DEC-10.

Aplikacija seveda nima neposredne zveze $\mathrm{z}$ GIS, vsaj $\mathrm{v}$ konvencionalnem smislu ne, je pa lep primer uporabe precej nenatančnega in še dodatno generaliziranega digitalnega modela reliefa pri zelo preciznih izračunih. 


\section{ZAKLJUČEK - UPORABNOST APLIKACIJ IN KVALITETA DMR}

V članku je opisana natančnost in uporabna vrednost uradnega DMR-100, za primerjavo pa je navedena še alternativna varianta baze reliefa v obliki digitalnih plastnic. Razlika je več kot očitna, vendar v okviru te razprave nisem imel namena favorizirati katerekoli izmed rešitev. V poglavju 5. je namreč predstavljenih pet aplikacij, za katere nam DMR-100 v celoti zadošča. Pri tem je koristno vedeti, da je natančnost izbrane aplikacije (E) lahko izražena kot konvolucija funkcije aplikacije (w) in funkcije natančnosti modela reliefa (e), kar splošno zapišemo kot $E=w \star e$ (Oestman 1987). To pa praktično pomeni, da lahko izračunamo do katere velikosti celic DMR lahko $z$ izbrano aplikacijo dobimo rezultate, ki bodo zadostili našim zahtevam natančnosti.

V zgoraj opisanih primerih smo vsaj približno vedeli za natančnost DMR-100, ki ni ravno visoka, pa vendar lahko zaključim, da smo kljub vsemu $z$ doseženimi rezultati zadovoljni. Razumeti moramo seveda, da natančnejši zajem takšnih podatkov pomeni tudi skokovito povečanje cene celotne aplikacije.

\section{LITERATURA IN VIRI}

Banovec, T., Lesar, A., 1975: Digitalni model reliefa Slovenije, PIS SRS II.faza, elaborat št.2, Ljubljana.

Brigham, E.O., 1988: The fast Fourier transform and its applications, Prentice-Hall, Inc., Englewood Cliffs, New Jersey.

Imhof, E., 1965: Kartographische Gelaendedarstellung, Walter de Gruyter \& Co., Berlin.

Kraus, K., 1984: Photogrammetrie, Band 2, Theorie und Praxis der Auswertsysteme, Ferd. Dummlers Verlag, Bonn.

Makarovič, B., 1972: Information transfer in reconstruction of data from sampled points, Photogrammetria, Vol.28, No.4.

Oestman, A., 1987: Accuracy estimation of digital elevation data banks, Photogrammetric Engineering \& Remote Sensing, Vol.53, No.4.

Radovan, D., 1984a: Optimizacija digitalnega modela reliefa za račun topografskih odklonov vertikale, diplomska naloga, 130 strani, Fakulteta za arhitekturo, gradbeništvo in geodezijo, Ljubljana.

Radovan, D., 1984b: Optimiranje digitalnega modela reliefa za računanje topografskih odklonov vertikale, Geodetski vestnik, Letnik 28, St.4.

Radovan, D., 1988a: Prostorske interpolacijske metode v avtomatizirani kartografiji, seminarska naloga na podiplomskem študiju, 121 strani, Fakulteta za arhitekturo, gradbeništvo in geodezijo, Ljubljana.

Radovan, D., 1988b: Interpolacijske metode $v$ tematski kartografiji, raziskovalna naloga PORS, Inštitut za geodezijo in fotogrametrijo, Ljubljana.

Radovan, D., 1990a: Nekateri problemi reagregacije prostorskih podatkov 
pri arealnih interpolacijskih metodah, magistrska naloga, 131 strani, Fakulteta za arhitekturo, gradbeništvo in geodezijo, Ljubljana.

Radovan, D., 1990b: Korekture in analiza digitalnega modela reliefa Republike Slovenije, tehnično poročilo, 16 strani, Inštitut za geodezijo in fotogrametrijo, Ljubljana.

Radovan, D., 1992a: Kompjuterizacija evidenc geodetske službe, Digitalni informacijski sistem reliefa, Metodološko-tehnološka nastavitev, raziskovalna naloga MVOUP, tehnično poročilo, 41 strani, Inštitut za geodezijo in fotogrametrijo, Ljubljana.

Radovan, D., 1992b: Analitično kartografsko senčenje DMR s psevdoslučajnostnimi rastri, Geodetski vestnik, Letnik 36, Št.3.

Rozman, J., 1991: Programski paket za izračun in prikazovanje območja oddajanja radiotelevizijskih oddajnikov, priročnik, 24 strani, Inštitut za geodezijo in fotogrametrijo, Ljubljana.

Rozman, J., Radovan, D., 1985: Uporaba laserske elektrografije pri računalniškem stavljanju tekstov in slik ter pri računalniški kartografiji, raziskovalna naloga PORS, Inštitut za geodezijo in fotogrametrijo, Inštitut Jožef Stefan, Inštitut za celulozo in papir, Ljubljana.

Rozman, J., Radovan, D., 1992: Digitalni model reliefa, priročnik programskega paketa, Ver. 3.0, 35 strani, Inštitut za geodezijo in fotogrametrijo, Ljubljana.

Vodopivec, F., Radovan, D., Kilar, B., 1985: Raziskava ploskve geoida v SRS, raziskovalna naloga RSS, Fakulteta za arhitekturo, gradbeništvo in geodezijo - oddelek za geodezijo, Ljubljana. 